\title{
The Psychology of Vaccine Hesitancy: How Health Providers May Help
}

Carlos Fayard, PhD, Lisa M. Fayard, MD

"Health care providers have correctly been called "heroes" during this pandemic. As vaccines have become available, they are now able to continue to save lives by encouraging their patients to get vaccinated. Are there ways to help overcome vaccine hesitancy?"

Health care providers have correctly been called "heroes" during this pandemic. As vaccines have become available, they are now able to continue to save lives by encouraging their patients to get vaccinated. Are there ways to help overcome vaccine hesitancy?

Among the most harmful and deadly features of the pandemic are the psychological factors (i.e., beliefs and behaviors) from the impact of the initial lockdown (1) to the embracing of mitigation measures (2), coping with pandemic fatigue (3), and now vaccine hesitancy (4). Attention to actionable, evidence-based psychological issues has been scarce.

A few months ago, my wife and I joined a WhatsApp group created by our former High School classmates as we are approaching the $50^{\text {th }}$ graduation anniversary. We enjoyed seeing pictures of their children and grandchildren, their gardens and homes, and stories of old. We were not prepared to see the intense reaction of many to the pandemic and now the vaccines. "Covid is a hoax," "this is a maneuver from those in power to control the people," "the vaccines are dangerous," "if you get vaccinated, you are a guinea pig," "trust the natural remedies instead," "where do you place your trust? Weren't you supposed to trust God?". There are a couple of physicians, a handful of nurses, including one who had oversight on vaccination programs at a large city among the skeptics. A brief and excellent video explanation of the Covid vaccines by a professor and expert from a well-known University was summarily dismissed as "misinformed." Even when our sister-in-law died from Covid, the naysayers did not express words of condolences, even though we all have a common religious background.

I do not know how prevalent this sentiment is among your patients and the community where you live, but most agree that getting vaccinated is critical to turning the tide of the pandemic and protecting lives (5). "Vaccine hesitancy" is how researchers are describing this phenomenon. The situation and arguments surrounding Covid are fairly unique to this virus. However, the behavior and beliefs about vaccination are not radically different from those seen in the past regarding other medical conditions (6).

How are we to understand vaccine hesitancy? Might we play a constructive role with our patients, their families, and members of our surrounding communities in decreasing the suspicion and even countering the misinformation?

\section{Beliefs, Behaviors and Vaccine Hesitancy}

There is nothing new about people being hesitant about medical treatments and vaccines. The pandemic, however, has made it imperative that most of us get vaccinated to achieve herd immunity. Vaccine hesitancy refers to delay in acceptance or refusal of vaccination despite the availability of vaccination services. Research suggests five main individual-level determinants of vaccine hesitancy: confidence, complacency, convenience (or constraints), risk calculation, and collective responsibility (7). Confidence denotes trust in the effectiveness and safety of vaccines. Complacency is said to occur when perceived risks of vaccinepreventable diseases are low, and vaccination is not considered necessary ("Covid only affects a very small percentage of the population" or "it is curable in the majority of the cases"). Constraints denote barriers to access vaccination. "Risk calculation indicates a deliberate comparison of the risks of infection versus those of vaccination, from which to derive a decision ("nobody knows if the vaccine provides true protection over time"). Collective responsibility refers to the willingness to protect others by one's own vaccination ("I'll let others get vaccinated to achieve herd immunity," putting one's interest ahead of those of the community).

\section{"Collective responsibility refers to the willingness to protect others by one's own vaccination ("'I"Ill let others get vaccinated to achieve herd immunity," putting one's interest ahead of those of the community)."}

You can see the salience of beliefs and behaviors for each one of these drivers of vaccine hesitancy. Let me highlight the role of confidence or trust. A recent study in the United Kingdom highlights the role of confidence in the information for those accepting the vaccine and those who are hesitant about it, "those resistant to a COVID-19 vaccine were less likely to obtain information about the pandemic from traditional and authoritative sources and had higher levels of mistrust in these sources compared to vaccine accepting respondents." (8) Paying attention to the role of emotions is essential. Psychologist and Public Health scientist Perry Halkitis puts it this way, "emotions and psychosocial conditions too often usurp logic and reason, which in turn fuel disease... experts tend to overlook medical mistrust, fear/avoidance, and stigma." (9) In fact, we are talking about very distinct areas of the brain that process rational information and emotion-based reactions. Emo-

NEONATOLOGY TODAY is interested in publishing manuscripts from Neonatologists, Fellows, NNPs and those involved in caring for neonates on case studies, research results, hospital news, meeting announcements, and other pertinent topics.

Please submit your manuscript to: LomaLindaPublishingCompany@gmail.com 
tions then, more than logic, drive misinformation, disinformation, and conspiracy theories about the vaccine.

\section{Misinformation, Disinformation and Conspiracy Theories}

Disinformation (strategically and deliberately spread false information), misinformation (false information, not necessarily with intent to mislead), and mistrust (more than the lack of trust; suspicion of ill intent - what is commonly referred to as "conspiracy theories") fuel fear, promote avoidance and become the "rationale" to be hesitant about the vaccination process. Conspiracy beliefs are "attempts to explain the ultimate cause of an event... as a secret plot by a covert alliance of powerful individuals or organizations, rather than as an overt activity or natural occurrence. It can be difficult to persuasively present evidence to refute these types of ideas, especially because experts are often seen as part of the conspiracy. New pieces of contrary evidence can be rationalized into an existing narrative" (10)

$\checkmark$ L. Our former classmates engaged in misinformation (e.g., "nobody knows how the vaccine affects your genes") and echoed conspiracy theories (e.g., "pharmaceutical companies are out to make money instead of promoting natural remedies"). Schwarz (11) researched the conditions under which individuals decide whether the information is acceptable: is it compatible with information previously known? Is the source credible? Do others perceived as belonging to one's group believe it as well? Is the information consistent? Is there some evidence to support it?

While fear and mistrust may guide some beliefs, reactance psychology informs the motivational state of those who feel their freedoms being curtailed (12). You can see why our classmates summarily dismissed our expert's explanation. He aimed at the part of the brain dealing with reason while our classmates processed their understanding with the part of the brain that deals with emotions.

\section{How Health Providers May Help?}

Could we help address vaccination hesitancy, misinformation, and even conspiracy beliefs as a health community? Could we help by more directly addressing the fears/avoidance vaccine hesitation? I believe we could. Let me share a few ways to do this based on some of my work consulting with a faith community serving a population riddled with vaccine hesitation.

1- Maintain yourself well informed regarding the development, efficacy, and safety of the vaccine. Find ways to transmit this message at the patient level, be it a farmer or a pharmacist.

2- Tailor the message to the understanding (or misunderstanding) and biases of those you meet. You will fairly quickly learn whether you are dealing with misinformation (which can be corrected with more accurate information), mistrust (which can be addressed by recognizing the fear) or conspiracy theories (which will not be persuaded by information but rather by affirming the importance of protecting their individual rights).

\section{New subscribers are always welcome!}

NEONATOLOGY

\section{To sign up for a free monthly subscription, just click on this box to go directly to our subscription page}

3- Follow general bedside principles, such as empathy with those who are fearful, when appropriate; disclose something personal that can help make a more personal connection; do not shame the person, but rather provide the information in a non-confrontational manner; avoid arguing about the veracity of the conspiratorial ideas (13). Health care providers who have a strong working alliance with their patients are most likely to influence their beliefs (14).

4- $\quad$ Evoke a sense of hope and altruism (15). One of the best examples of this approach is the commercial featuring singer John Legend where he starts by saying, "this shot is our shot, our opportunity to return to the places, the faces that we love and miss," "we are ready when you are ready." As he speaks, you can see in the background people coming together, sharing happy moments after the initial image of health professionals masked and gloomy music. Being a commercial, he points to the organization sponsoring the ad, but he says, "These are the pharmacies you know, with the people you know." Legend's ad highlights hope, connection, altruism, and trust.

5- Lead by example. Share in your social media not only that you received your shot but also that you had some discomfort but recovered quickly. Hesitant people may be fearful of side effects. This is a sort of "psychological vaccine," where sharing some personal information that connects to portions already believed by the hesitant and skeptic may "inoculate" against misinformation (16)

6- Build partnerships with trusted individuals and organizations in your community. For instance, spiritual leaders play a powerful role, particularly in communities of color. You can partner with a leader to help address the fears and beliefs present in the community. Here are some of the fears/beliefs in the faith community I consulted with: "Getting the vaccine shows a lack of faith in God's protection and power", "I trust in natural and spiritual remedies," "I am young and healthy," "I don't trust science, I only trust the Word of God," "I don't trust the government." You can make yourself available to be interviewed by the spiritual leader to address these concerns. Be non-defensive and acknowledge that some of the messaging has been confusing (remember when we were told that masking did not help?) You can serve as a bridge to bring your health organization to the community and increase access and harness their credibility by sharing information in non-jargon language, having their location become a vaccination site (17), be it in their church, school, gym.

7- Be courageous and realistic. Talking about these issues can result in intense reactions. Remember that emotions usurp logic and reason. Be courageous and keep in mind that you will not be able to "win them all." Just aim at moving the needle in the right direction.

John Legend goes on to emphasize the theme "this is our shot." "Our shot to get back our communities together, providing healing not for some but for all," "reconnecting with the ones we love, with the world we lost. This is our shot". As a health professional, you too have a shot. Indeed, through you, this becomes "our shot."

\section{References:}

1. Holland KM, Jones C, Vivolo-Kantor AM, Idaikkadar N, Zwald M, Hoots B, et al. Trends in US Emergency Department Visits for Mental Health, Overdose, and Violence Outcomes Before and During the COVID-19 Pandemic. JAMA Psychiatry. 2021;78(4):372-9. Epub 2021/02/04. doi: 10.1001/jamapsychiatry.2020.4402. PubMed PMID: 33533876; PubMed Central PMCID: PMCPMC7859873.

2. Kavanagh NM, Goel RR, VenkataramaniAS. County-Level Socioeconomic and Political Predictors of Distancing for COVID-19. Am J Prev Med. 2021. Epub 2021/05/06. doi: 10.1016/j.amepre.2021.01.040. PubMed PMID: 
33947527: PubMed Central PMCID: PMCPMC7988444. Reicher S, Drury J. Pandemic fatigue? How adherence to covid-19 regulations has been misrepresented and why it matters. BMJ. 2021;372:n137. Epub 2021/01/20. doi: 10.1136/bmj.n137. PubMed PMID: 33461963.

4. Troiano G, Nardi $A$. Vaccine hesitancy in the era of COVID-19. Public Health. 2021;194:245-51. Epub 2021/05/10. doi: 10.1016/j.puhe.2021.02.025. PubMed PMID: 33965796.

5. Wiysonge CS, Ndwandwe D, Ryan J, Jaca A, Batoure O, Anya BM, et al. Vaccine hesitancy in the era of COVID-19: could lessons from the past help in divining the future? Hum Vaccin Immunother. 2021:1-3. Epub 2021/03/09. doi: 10.1080/21645515.2021.1893062. PubMed PMID: 33684019.

6. Marshall GS. Vaccine Hesitancy, History, and Human Nature: The 2018 Stanley A. Plotkin Lecture. J Pediatric Infect Dis Soc. 2019;8(1):1-8. Epub 2019/03/28. doi: 10.1093/jpids/piy082. PubMed PMID: 33513237.

7. MacDonald NE, Hesitancy SWGoV. Vaccine hesitancy: Definition, scope and determinants. Vaccine. 2015;33(34):4161-4. Epub 2015/04/22. doi: 10.1016/j. vaccine.2015.04.036. PubMed PMID: 25896383.

8. Murphy J, Vallieres F, Bentall RP, Shevlin M, McBride O, Hartman TK, et al. Psychological characteristics associated with COVID-19 vaccine hesitancy and resistance in Ireland and the United Kingdom. Nat Commun. 2021;12(1):29. Epub 2021/01/06. doi: 10.1038/s41467020-20226-9. PubMed PMID: 33397962; PubMed Central PMCID: PMCPMC7782692.

9. Halkitis PN. A new public health psychology to mend the chasm between public health and clinical care. Am Psychol. 2020;75(9):1289-96. Epub 2021/01/01. doi: 10.1037/amp0000743. PubMed PMID: 33382297.

10. Jaiswal J, LoSchiavo C, Perlman DC. Disinformation, Misinformation and Inequality-Driven Mistrust in the Time of COVID-19: Lessons Unlearned from AIDS Denialism. AIDS Behav. 2020;24(10):2776-80. Epub 2020/05/23. doi: 10.1007/s10461-020-02925-y. PubMed PMID: 32440972; PubMed Central PMCID: PMCPMC7241063.

11. Schwarz N. Metacognition In: Borgida EaB, J., editor. APA Handbook of Personality and Social Psychology. 1. Washington, DC2015.

12. Taylor S, Landry CA, Paluszek MM, Groenewoud R, Rachor GS, Asmundson GJG. A Proactive Approach for Managing COVID-19: The Importance of Understanding the Motivational Roots of Vaccination Hesitancy for SARS-CoV2. Front Psychol. 2020;11:575950. Epub 2020/11/17. doi: 10.3389/fpsyg.2020.575950. PubMed PMID: 33192883; PubMed Central PMCID: PMCPMC7604422.

13. Wallis C. The Best Evidence for How to Overcome COVID Vaccine Fears2021. Available from: https://www.scientificamerican.com/article/the-best-evidence-for-howto-overcome-covid-vaccinefears $1 /$.

14. Orom H, Underwood W, 3rd, Cheng Z, Homish DL, Scott I. Relationships as Medicine: Quality of the PhysicianPatient Relationship Determines Physician Influence on Treatment Recommendation Adherence. Health Serv Res. 2018;53(1):580-96. Epub 2016/12/17. doi: 10.1111/1475-6773.12629. PubMed PMID: 27981559; PubMed Central PMCID: PMCPMC5785307.

15. Chou WS, Budenz A. Considering Emotion in COVID-19 Vaccine Communication: Addressing Vaccine Hesitancy and Fostering Vaccine Confidence. Health Commun. 2020;35(14):1718-22. Epub 2020/10/31. doi: 10.1080/10410236.2020.1838096. PubMed PMID: 33124475 .
16. Lewandowski S. The Debunking Handbook2020.

17. Abdul-Mutakabbir JC, Casey S, Jews V, King A, Simmons $K$, Hogue MD, et al. A three-tiered approach to address barriers to COVID-19 vaccine delivery in the Black community. Lancet Glob Health. 2021. Epub 2021/03/14. doi: 10.1016/S2214-109X(21)00099-1. PubMed PMID: 33713634; PubMed Central PMCID: PMCPMC7946412.

Disclosures: The authors have no relevant disclosures.

NT
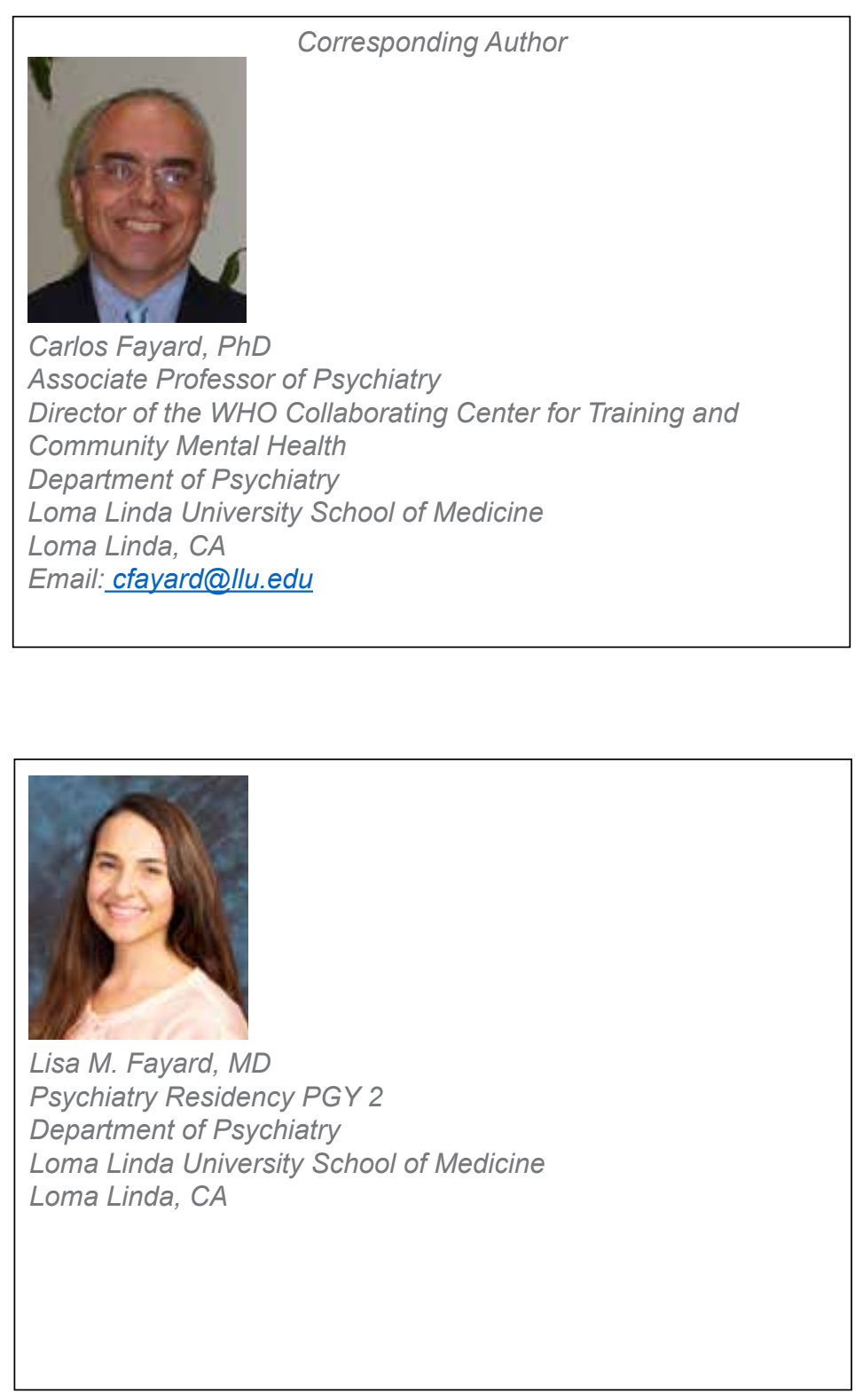